\title{
INFLUENCE OF ANTI-SCUFFING AND ANTI-GALLING PROPERTIES IN OILS ON HYPOID GEAR GALLING.
}

\author{
Ing. Pavol SLOVÁK, PhD.
}

Slovak University of Technology Bratislava, Institute of Transportation Technology and Design Nám. Slobody 17, 81231 Bratislava, pavol.slovak@stuba.sk

\begin{abstract}
The paper presents (in shorter form) the values of lubricant anti-galling factor for various hypoid oils and also the comparison of these factors in the galling of four tested hypoid gears OERLIKON. The results were obtained from laboratory and performance experiments.
\end{abstract}

KEYWORDS: antiscuffing, antigalling, hypoid gear, antigalling factor.

\section{INTRODUCTION}

Conical gears with a shifted axis (known as hypoid gears) produce slipping in the direction of tooth height and also in the longitudinal direction along the tooth. These adverse slip rates cause material transfer and wear on the teeth, otherwise known as galling. This form of wear has a significant effect on the value of transmitting power. Extensive experimental investigations allow us to better understand the galling process in hypoid gears [1]. The calculation of galling wear capacity is based on the integral temperature method. This method for spur gears is given in standard DIN 3990 proposal.

\section{METHOD}

The galling safety Ss int can be expressed:

$$
S_{S \text { int }}=\frac{\vartheta_{S \text { int } T}}{\vartheta_{\text {int }}}
$$

and in accordance to the DIN 3990 standard the magnitude of integral temperature (the temperature, which causes the gearing to seized) can be written:

$$
\vartheta_{\text {int }}=\left(\vartheta_{\text {oil }}+C_{1} \cdot \vartheta_{\text {fla int }}\right) \cdot X_{S}+C_{2 H} \cdot \vartheta_{\text {fla int }}
$$

and the temperature at which the oil becomes ineffective:

$$
\vartheta_{S \text { int } T}=\vartheta_{M T}+C_{2} \cdot \vartheta_{\text {fla int } T} \cdot X_{\text {WrelT }}
$$

Remark: the galling temperature values determined in accordance to [3] are considered only from point of view of kinematic oil viscosity (e.g. hypoid oils chosen for testing comply requirements of MIL - L - 2105 C [3] specification, i.e. the lubricant has guaranteed galling force grade $>12$ (FZG test A $10 / 8,3 / 90$, galling moment $\mathrm{M}_{1 \mathrm{~T}}=800 \mathrm{Nm}$ and oil temperature $\vartheta_{\text {oilT }}=90^{\circ} \mathrm{C}$ ). The influence of high pressure additives is not taken into consideration and this fact considerably misinterprets results confirmed by anti-scuffing and anti-galling tests of hypoid oils [4] and confirms the importance of such tests. For this reason the anti-galling lubricant factor is introduced to improve the precision of galling temperature determination.

The anti-galling lubricant factor takes into the consideration the influence of high pressure and lubricant additives in dependence to galling temperature. The presence of high pressure additives and theirs properties in tested hypoid oils are documented by anti-scuffing and anti-galling tests [4]. 
The anti-galling lubricant factor was on the basis of these measurements and performance tests of hypoid oils [4] determined as follows:

$$
K_{Z T}=\sqrt{\frac{I_{h}}{100}+O_{0}}
$$

where $\mathrm{I}_{\mathrm{h}}$ - wear resistance factor, $\mathrm{O}_{0}$ - relative wear resistance [5].

The values of anti-galling factor (in accordance to equation 4) for various oil types are given at fig. 1 .

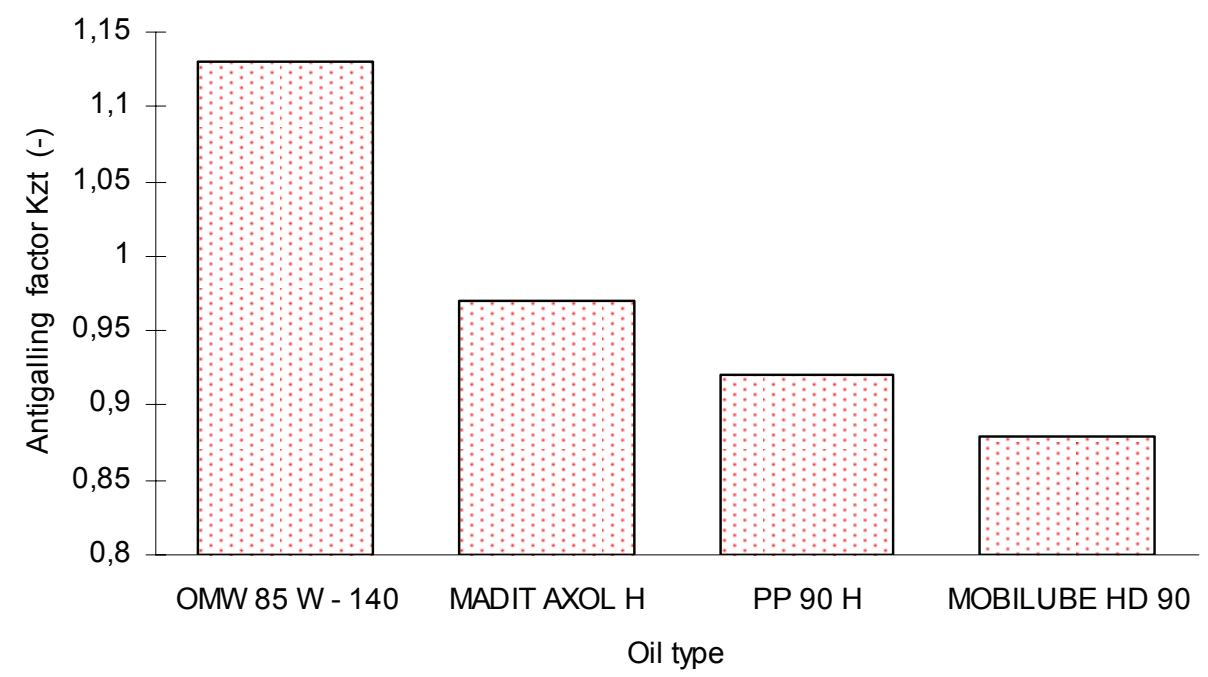

Fig. 1 Anti-galling factor $K_{Z T}$ for various oil types.

Taking into the consideration anti-galling lubricant factor $\mathrm{K}_{\mathrm{ZT}}$, the equation (3) will modify as follows:

$\vartheta_{S \text { int } T}=\vartheta_{M T}+C_{2} \cdot \vartheta_{\text {fla int } T} \cdot X_{\text {WrelT }} \cdot K_{Z T}$

\section{MEASURMENT}

The galling temperatures of hypoid oils considering anti-galling lubricant factor $\mathrm{K}_{\mathrm{ZT}}$ are given at fig.2. The highest value of galling temperature has clearly oil OMW $85 \mathrm{~W} 140-930^{\circ} \mathrm{C}$, other oils (MADIT AXOL $\mathrm{H}-819,2^{\circ} \mathrm{C}$, PP $90 \mathrm{H}-809,9^{\circ} \mathrm{C}$ and MOBILUBE HD $90-782,81^{\circ} \mathrm{C}$ ) have lower temperature values. This fact is due to various of EP additives in the oils. Former analysis confirmed tendency to decrease oil viscosity value and enrich basic medium with high pressure and other additives which improve oil properties. 


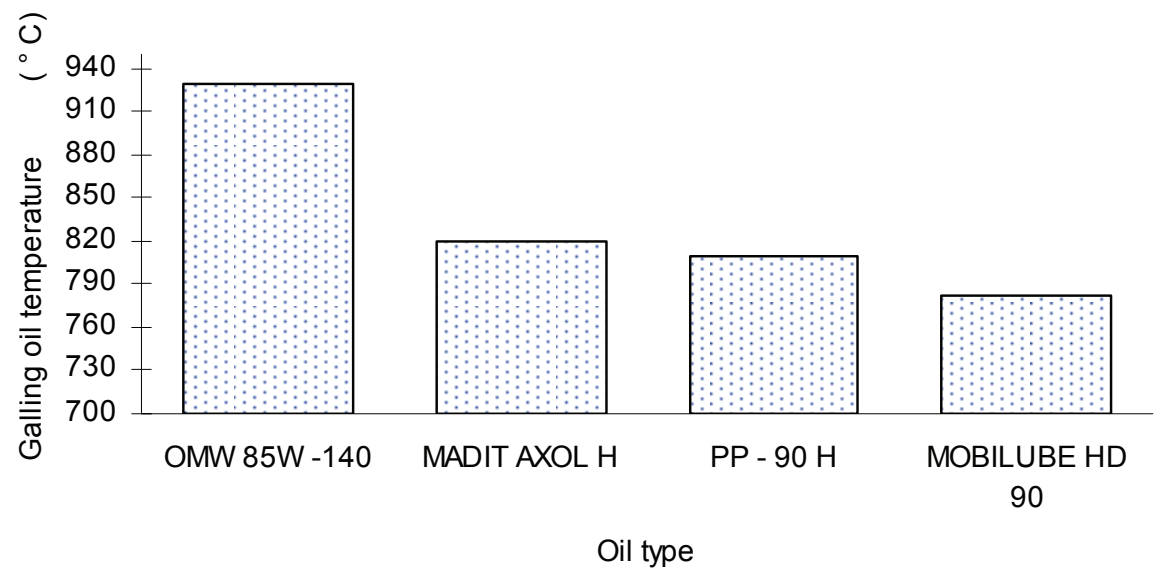

Fig. 2 Comparison of galling temperatures of various oils considering galling factor $K_{Z T}$.

\section{CONCLUSION}

Fig.3 shows comparison of integral temperatures for various gearing types and oil types in accordance to (2).

Fig.4 shows relative galling safeties for various gearings using all testing oils. All values are compared to gearings 39/8 (galling safety $\mathrm{S}_{\mathrm{Sint}}=2,363$ ), used oil Mobilube HD 90, torque moment $\mathrm{M}_{1}=7000 \mathrm{~N}$.m, pinion revolutions $\mathrm{n}_{1}=300 \mathrm{~min}^{-1}$. The most favorable values of galling safety for all gearings type were obtained using oil OMW $85 \mathrm{~W}-140$. From the geometry point of view the highest value of galling safety was obtained using gearings 43/11 (3,16 - 133\%) and 49/9 (3.09$131 \%)$, then gearings $37 / 9(2,94-124.3 \%)$ and $39 / 8(2,81-118.8 \%)$. For all these gearings was used oil OMW $85 \mathrm{~W}-140$.

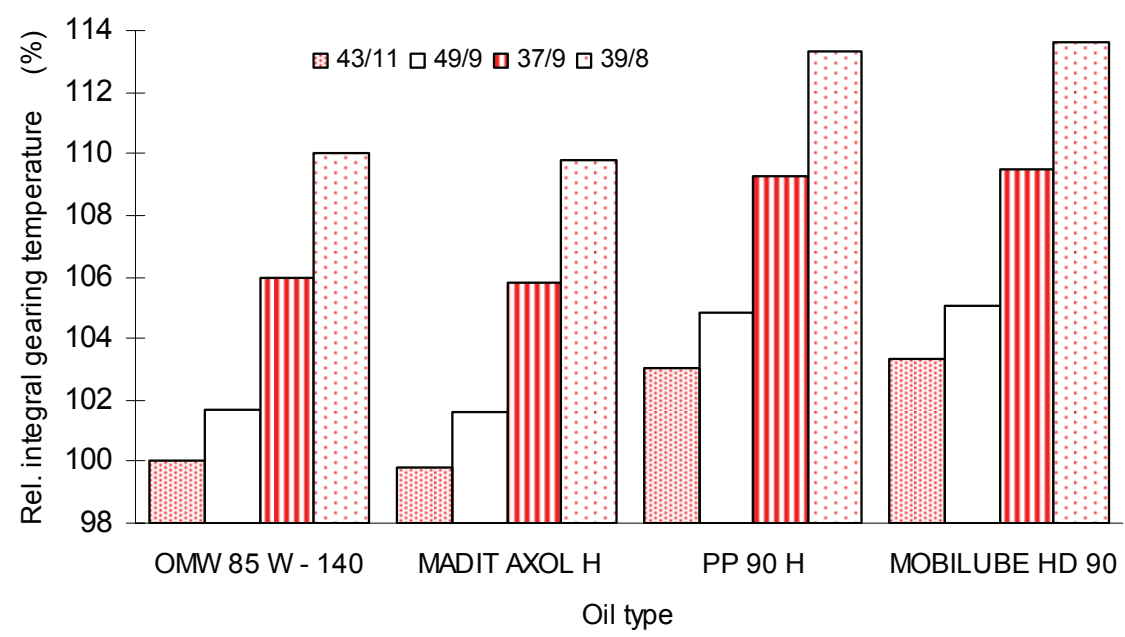

Fig. 3 Relative integral gearing temperature. 


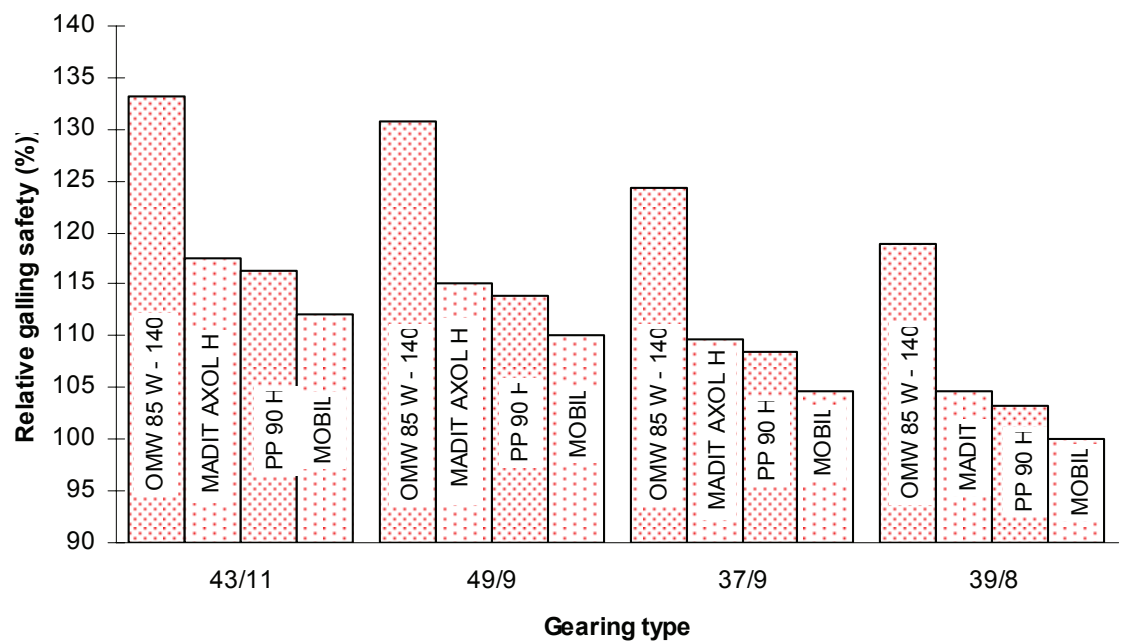

Fig. 4 Relative galling safety.

\section{REFERENCES}

[1] RICHTER, M.: Der Verzahnungswirkungsrad und die Frestragfähigkeit von Hypoid - und Schraubenradgetrieben. Diss. TU München, 1976

[2] DIN 3990: Grundlagen für die Tragfähigkeitsberechnung von Gerad - und Schästirnrädern. Entwurz Märtz 1980

[3] DIN 51 354: Mechanische Prüfung von Getriebeölen in der FZG - Zahnrad - Verspannungs Prüfmaschine, Teil 1 und Teil 2, 1977

[4] SLOVÁK, P.: Rozbor tribologických charakteristík z hl'adiska únosnosti a trvanlivosti prevodových systémov, Dizertácia, STU SjF Bratislava, 1997

[5] STN 65 6254: Metóda stanovenia protioderových a protizadieracích vlastností mazacích olejov a kvapalín na štvorgul'kovom stroji, 1987. 